\title{
ACOMPANHAMENTO POR ESPECTROSCOPIA DE INFRAVERMELHO (FTIR) DA DEGRADAÇÃO DO DIESEL E DO BIODIESEL POR PSEUDOMONAS AERUGINOSA
}

\author{
D. L. R. RIBEIRO ${ }^{1}$, S. T. S. VERAS ${ }^{1}$, J. G. A. PACHECO FILHO ${ }^{1}$, G. M. de CAMPOS-TAKAKI ${ }^{2}$ e \\ M.de L. A. P. F. PALHA ${ }^{1}$ \\ ${ }^{1}$ Universidade Federal de Pernambuco, Departamento de Engenharia Química \\ ${ }^{2}$ Universidade Católica de Pernambuco, Núcleo de Pesquisa em Ciências Ambientais e Biotecnologia \\ E-mail para contato: dafne.luana@hotmail.com.br
}

\begin{abstract}
RESUMO - O crescente consumo de derivados de petróleo, na atualidade, intensificou a frequência de acidentes decorrentes de vazamentos de óleo. Diante disto, diversas tecnologias de degradação vêm sendo desenvolvidas, destacando-se entre elas a biodegradação. Neste contexto, foi verificada a degradação do Diesel e biodiesel pela bactéria $P$. aeruginosa, onde o acompanhamento da biodegradação dos compostos foi realizado através da análise por espectroscopia de infravermelho (FTIR) das alíquotas retiradas a cada 4 horas, do ensaio de biodegradação, por um período de 72 horas. Os espectros obtidos a partir da análise por infravermelho demonstraram a modificação dos grupos funcionais, presentes na amostra inicial do processo, atribuídos ao consumo do substrato (poluente) pela bactéria e formação de subprodutos. A biodegradação é justifica pelo fato do poluente ser a única fonte de carbono presente no meio utilizado para o ensaio de degradação. O ensaio foi eficaz na degradação dos compostos estudados.
\end{abstract}

\section{INTRODUÇÃO}

A intensificação da indústria petrolífera é diretamente proporcional ao aumento do risco de derramamentos de óleos tanto em águas territoriais, como em ecossistemas sensíveis da região costeira. Eventos deste tipo podem afetar de forma direta ou indireta as comunidades biológicas. A forma direta é dada através da sufocação e cobertura da superfície corporal ou pela exposição tóxica gerada pela absorção, inalação e ingestão. Enquanto que na maneira indireta, as comunidades biológicas podem ser afetadas pela perda de seu habitat. Os impactos podem afetar ainda áreas importantes diretamente para o homem, a exemplo temos os assentamentos populacionais, áreas de turismo, extração de recursos (pesca), aquicultura, mineração e locais de interesse cultural e arqueológico (Ernesto, 2010).

O comércio internacional do petróleo é baseado, essencialmente, no transporte marítimo, que está em constante expansão por conta do aumento da frota de petroleiros como também do tamanho 
destes. Significando desta maneira que assim como a probabilidade de acidentes cresceu, as consequências destes acidentes também aumentaram significativamente. A ocorrência dos grandes acidentes envolvendo derramamento de óleo demonstrou os prejuízos causados ao meio ambiente (Cardoso, 2007).

No Brasil, as regiões mais suscetíveis a derramamentos de petróleo e seus derivados são as zonas costeiras, já que são nas operações realizadas nos portos e terminais que se tem registrado os maiores índices de acidentes, cerca de 90,8\% do total (Silva, 2004). Os constantes acidentes ambientais envolvendo derramamentos de petróleo e seus derivados registrados em solos brasileiros vêm desencadeando a preocupação com o desenvolvimento de novas técnicas que objetivam, principalmente, a descontaminação dessas matrizes. Diante disso, diversos métodos, sejam eles: físicos, químicos e biológicos, vêm sendo desenvolvidos para a recuperação, remoção ou degradação in-situ ou ex-situ de petróleo derramado e consequentemente para a minimização de seus efeitos sobre o ecossistema, especialmente os tóxicos. Em meio às diversas técnicas desenvolvidas, a "biorremediação" destaca-se como uma alternativa viável e promissora para o tratamento desses ambientes impactados por petróleo e seus derivados (Bento et al., 2008; Dua et al., 2002; Rahman et al., 2002).

Sabe-se que com a instalação da Refinaria Abreu e Lima, no Porto de Suape - Pernambuco, provavelmente aumentará a incidência de problemas ambientais decorrentes de derramamento de petróleo e derivados (Souza, 2011). Diante da crescente necessidade de estudos de biodegradação de contaminantes de petróleo e derivados, foi realizado neste trabalho um ensaio com o objetivo de verificar a biodegradação do composto utilizando a bactéria $P$. aeruginosa. Visando a contribuição positiva para a comunidade científica no desenvolvimento e aplicação desta tecnologia.

\section{METODOLOGIA}

\subsection{Aclimatação da linhagem da bactéria Pseudomonas aeruginosa}

A aclimatação foi feita através da transferência de células de $P$. aeruginosa para placas de Petri contendo o meio sólido Luria Bertani (LB) [triptona (10g/L), extrato de levedura (5g/L), cloreto de sódio $(10 \mathrm{~g} / \mathrm{L})$ e Ágar $(15 \mathrm{~g} / \mathrm{L})]$, adicionado de $30 \%$ de Diesel. Em seguida, as placas foram mantidas em estufa sob temperatura de $30^{\circ} \mathrm{C}$ durante 24 horas. A linhagem de $P$. aeruginosa crescida neste meio adicionado de diesel foi utilizada para o ensaio de biodegradação dos combustíveis.

\subsection{Ensaio de degradação do Diesel e biodiesel}

O ensaio de degradação foi efetuado em frascos Fernbach com capacidade para 3L, contendo 2L de meio mineral Bushnell Hass $(\mathrm{BH})$ contendo $10 \%$ do substrato (diesel ou biodiesel), e utilizado um inóculo de 5\% do micro-organismo $P$. aeruginosa aclimatada a 30\%. As condições foram 
mantidas durante $72 \mathrm{~h}$ em agitação orbital de $150 \mathrm{rpm}$ e temperatura de $30^{\circ} \mathrm{C}$, durante esse período retirou-se alíquotas a cada $4 \mathrm{~h}$ com a finalidade de verificar a degradação dos poluentes.

\subsection{Acompanhamento da degradação por FTIR}

O acompanhamento da degradação foi realizado tomando como base o consumo de substrato e formação de produtos após o cultivo de $P$. aeruginosa aclimata em diesel. Desta forma, investigação foi efetuada pela técnica de infravermelho (FTIR), onde as amostras foram avaliadas em um equipamento da marca Bruker (modelo Tensor 27) com janelas de seleneto de zinco ( $\mathrm{ZnSe}$ ). Todas as amostras foram analisadas para obtenção de espectros na faixa de 4000 a $700 \mathrm{~cm}-1$ (Aliske et al., 2007) resolução de cm-1 e 150 scans. Os espectros foram obtidos através do método de Refletância Total Atenuada (ATR), que consistiu na adição de uma pequena quantidade de amostra centrifugada a 9000rpm durante 15 minutos a uma temperatura de $20^{\circ} \mathrm{C}$, e colocada com auxílio de uma fina espátula no suporte ATR platinum conectado ao equipamento de infravermelho, conforme representação na Figura 1. Posteriormente, o software do equipamento fornece o espectro de transmitância obtido. A retirada da amostra e limpeza do sensor é realizada com um lenço macio umedecido com álcool isopropílico e outro seco.

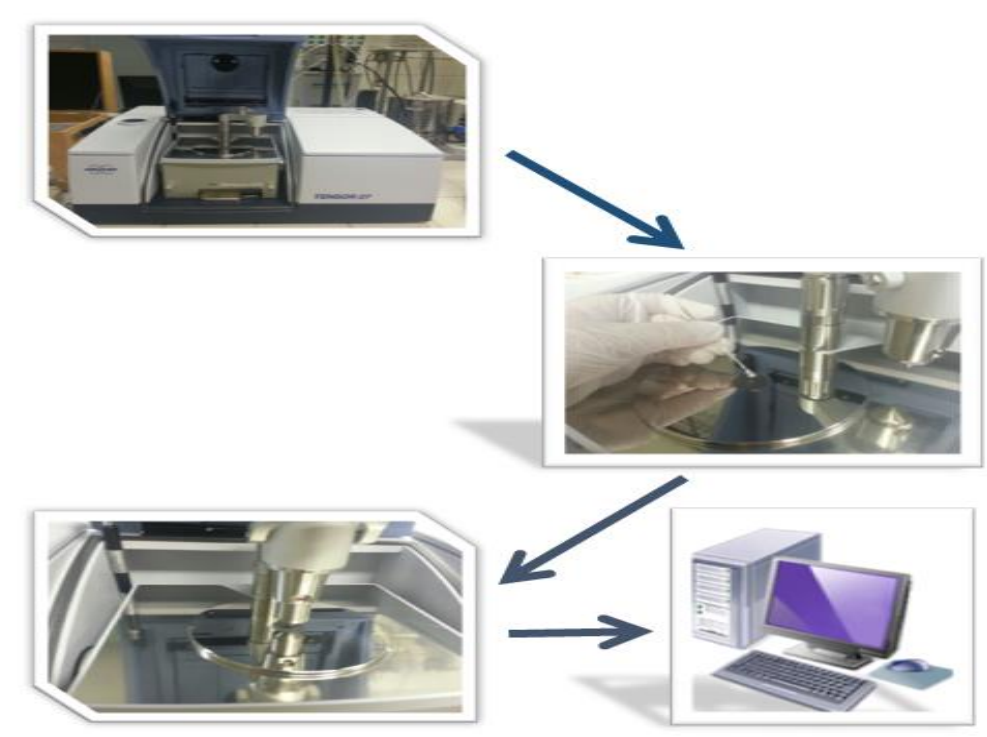

Figura 1 - Sequência simplificada para análise das amostras por infravermelho.

\section{RESULTADOS}

\subsection{Acompanhamento da degradação do Diesel}

O acompanhamento da biodegradação foi efetuado através da análise dos grupos funcionais 
presentes na amostra inicial e final, determinados através da análise de infravermelho (FTIR) realizada a partir das alíquotas retiradas durante o ensaio, possibilitando assim a identificação dos principais grupos funcionais presentes nas amostras. Como o combustível diesel apresenta uma constituição complexa, várias bandas foram observadas no espectro. A interpretação dos resultados foi feita com base em alguns trabalhos encontrados na literatura. Nas Figuras 2 e 3, é possível analisar a degradação do diesel através de comparações feitas entre a amostra inicial e final do ensaio de degradação.

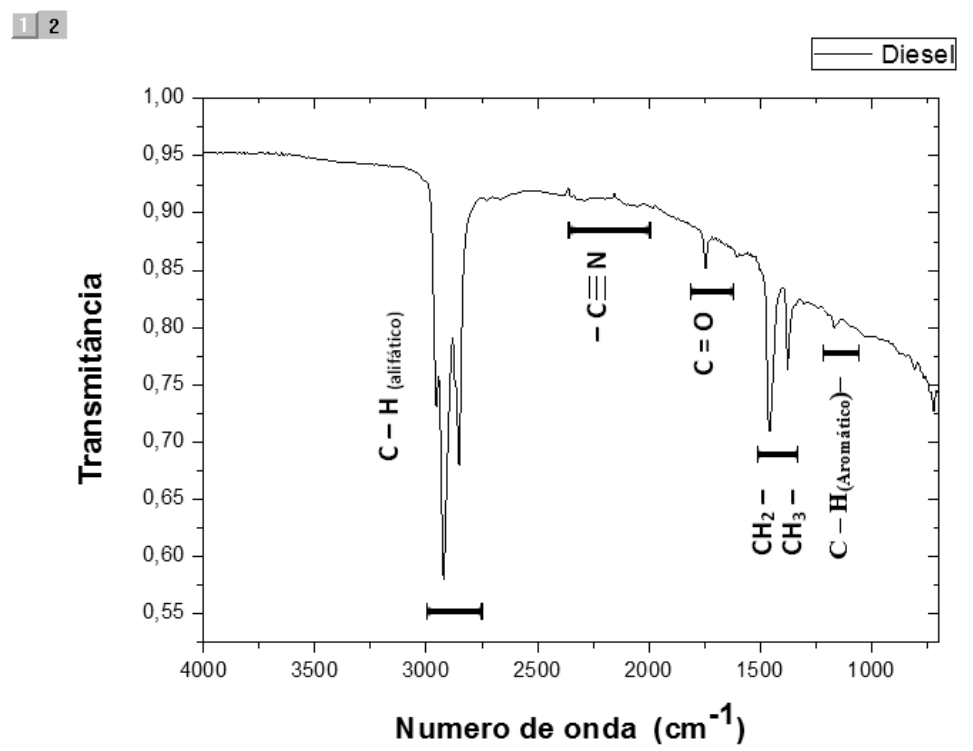

Figura 2 - Espectro do infravermelho referente amostra inicial do Diesel para degradação.

A análise da figura 2 demonstra a presença de $\mathrm{C}-\mathrm{H}$ nas bandas correspondentes ao comprimento de onda entre $3000-2800 \mathrm{~cm}^{-1}$, indicando a presença de cadeias alifáticas. A presença desses compostos também pode ser confirmada pelas vibrações entre $1500-1300 \mathrm{~cm}^{-1}$, característicos da presença de grupos $-\mathrm{CH}_{2}$ e $-\mathrm{CH}_{3}$ (Fonts et al., 2009; Dominguez, 2009). As bandas entre $2300-2000 \mathrm{~cm}^{-1}$ indicam ligações $\mathrm{C} \equiv \mathrm{N}$ e $-\mathrm{N}=\mathrm{C}$, enquanto que as vibrações $\sim 1700 \mathrm{~cm}^{-1}$ indicam ligações $\mathrm{C}=\mathrm{O}$, evidenciando a presença de compostos como ácidos carboxílicos, ésteres, aldeídos e cetonas. De acordo com Fonts et al. (2009) e Aliske et al. (2007) as bandas localizadas entre $1250-1100 \mathrm{~cm}^{-1}$ podem ser atribuídas a existência de ligações $\mathrm{C}-\mathrm{H}$ de cadeias aromáticas. Por outro lado, analisando-se a Figura 3 observa-se uma modificação na estrutura do composto original com surgimento de duas bandas mais largas. Esta mostra a presença de uma banda em torno de $3250 \mathrm{~cm}^{-1}$, podendo ser atribuídas a ligações de $\mathrm{O}-\mathrm{H}$ (associado), indicando a presença de água ou aminas, a banda forte, larga, depende da concentração da mesma. A vibração localizada $\sim 1650 \mathrm{~cm}^{-1}$ indica a possível presença de grupos -CONH, segundo Pokorna (2009). O comparativo entre as amostra demonstrou que houve 
degradação, uma vez que foi possível verificar a mudança dos grupos funcionais presentes na amostra inicial do processo.

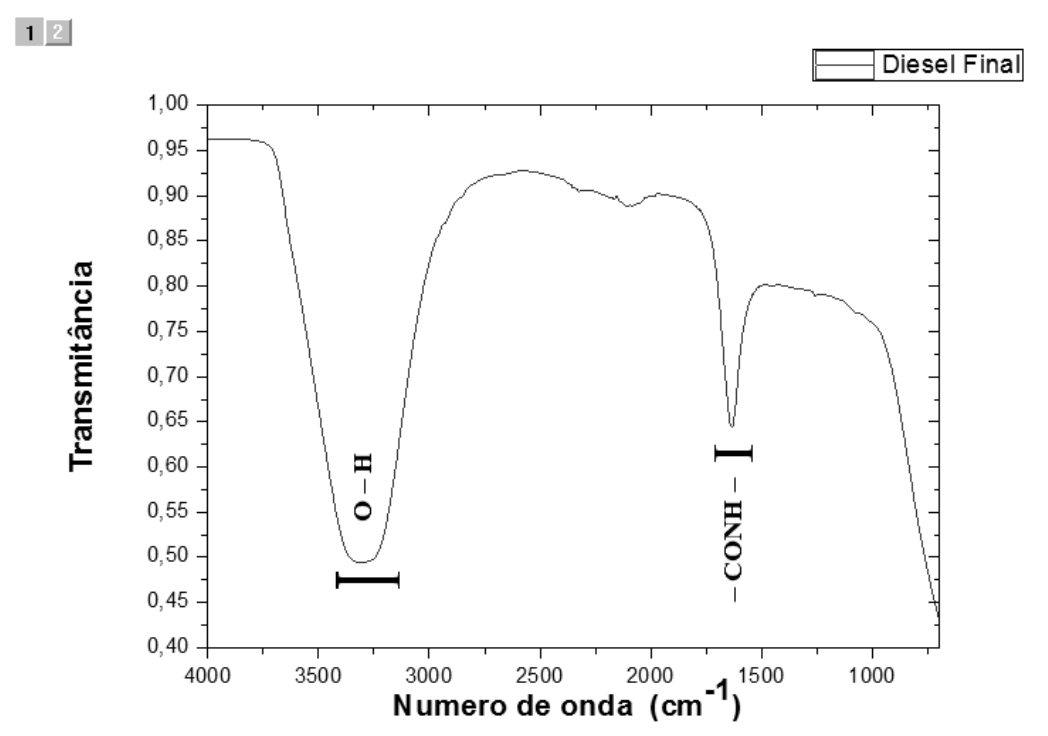

Figura 3 - Espectro do infravermelho referente amostra final do Diesel, demonstrando a degradação.

\subsection{Acompanhamento da degradação do biodiesel}

Assim como no ensaio descrito para o diesel, o acompanhamento da biodegradação foi efetuado através da análise dos grupos funcionais presentes na amostra inicial e final, determinados através da análise de infravermelho (FTIR). A interpretação dos resultados foi feita com base em alguns trabalhos encontrados na literatura Nas Figuras 4 e 5, é possível analisar o comportamento do biodiesel original e após a degradação.

A Figura 4 mostra o espectro do biodiesel com algumas bandas semelhantes ao diesel, possuindo desta forma interpretações semelhantes. As vibrações descritas são encontradas mais precisamente por volta de $3000-2800 \mathrm{~cm}^{-1}$, que indica a possível presença de ligações $\mathrm{C}-\mathrm{H}$ de cadeias alifáticas. De acordo com Dominguez (2009) e Fonts (2009) tais vibrações são confirmadas também pela presença das bandas localizadas entre $1500-1300 \mathrm{~cm}^{-1}$, atribuídas a ligações $-\mathrm{CH}_{2} \mathrm{e}$ $-\mathrm{CH}_{3}$, característicos de alcanos. Enquanto que as vibrações próximas a $2300 \mathrm{~cm}^{-1}$ são atribuídas a compostos nitrilados, indicando a presença de ligações $\mathrm{C} \equiv \mathrm{N}$ e/ou $-\mathrm{N}=\mathrm{C}$. As ligações entre grupos $\mathrm{C}=\mathrm{O}$, característicos de compostos como ácidos carboxílicos, ésteres, aldeídos e cetonas, foram observados na banda próxima a $1750 \mathrm{~cm}^{-1}$. As bandas localizadas em $1250-1100 \mathrm{~cm}-1$ podem ser atribuídas a existência de ligações $\mathrm{C}-\mathrm{H}$ de cadeias aromáticas, de acordo com os autores Fonts et al. 
(2009) e Aliske (2007).

Enquanto que após o processo de degradação, apresentado na Figura 5, o espectro apresenta bandas localizadas entre $3300 \mathrm{~cm}^{-1}$ que sugerem a existência de ligações $\mathrm{O}-\mathrm{H}$ (associado) podendo indicar a presença de água, álcoois, fenóis ou ácidos carboxilicos. Enquanto que as vibrações localizadas entre 1650 a $1550 \mathrm{~cm}^{-1}$ são atribuídas a grupos - $\mathrm{CONH}$, característicos de amidas (Fonts, 2009; Soares et al., 2011). Os espectros obtidos após degradação têm características semelhantes ao espectro do Diesel, porém é possível perceber no espetro pós degradação do biodiesel o surgimento de bandas pouco intensas entre 3000 - $2800 \mathrm{~cm}-1$ atribuídas a presença de ligações $\mathrm{C}-\mathrm{H}$ alifáticas e $\sim 2250 \mathrm{~cm}-1$ características de grupos nitrilados. Desta forma, é possível observar pelos espectros, que há modificação na estrutura do substrato original. As células bacterianas, por sua vez possuíram apenas o Diesel ou biodiesel como única fonte de carbono e apresentaram crescimento celular, portanto o Diesel ou o biodiesel foi utilizado, evidenciando a degradação do composto.

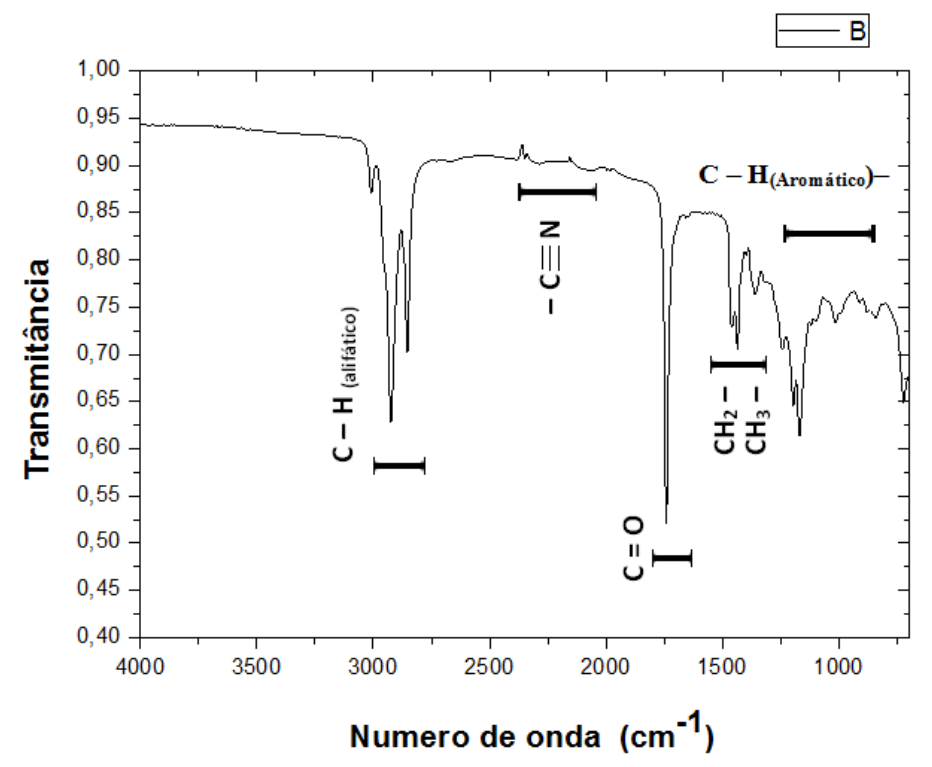

Figura 4 - Espectro do infravermelho referente amostra inicial do biodiesel para degradação. 


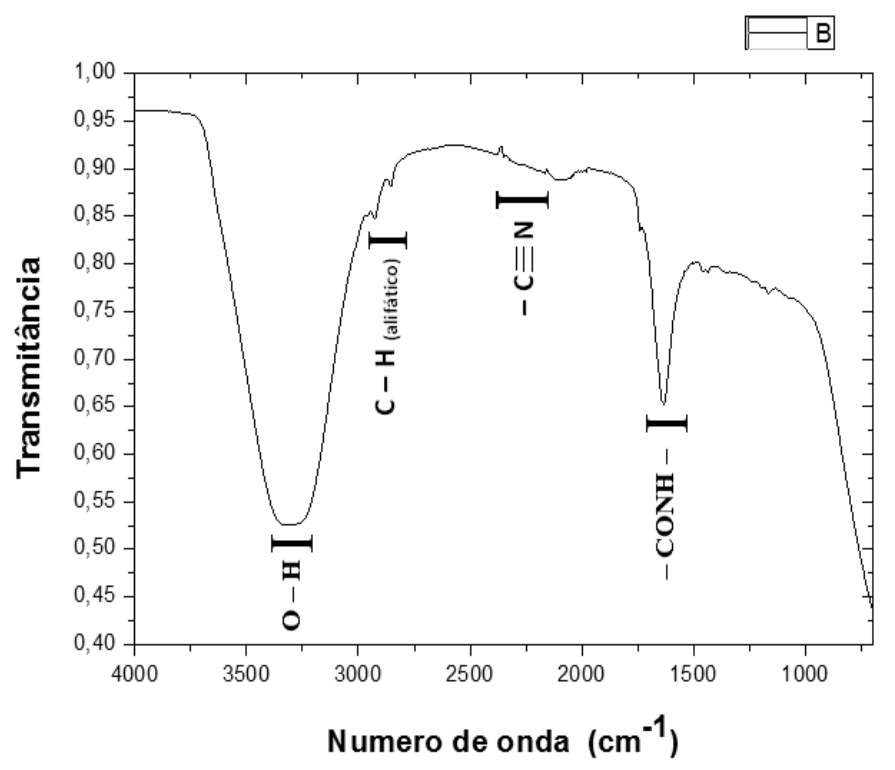

Figura 5 - Espectro do infravermelho referente amostra final do biodiesel, após a degradação.

\section{CONCLUSÕES}

Os espectros obtidos a partir da análise de infravermelho (FTIR) demonstraram uma modificação dos grupos funcionais presentes na amostra inicial do processo de biodegradação (diesel ou biodiesel), evidenciando que houve degradação do composto.

\section{AGRADECIMENTOS}

À ANP e à PETROBRAS, pelo fomento à pesquisa fornecido por meio do Programa de Recursos Humanos da ANP para o Setor de Petróleo e Gás - PRH 28, do Departamento de Engenharia Química, Centro de Tecnologia e Geociências da UFPE.

\section{REFERÊNCIAS}

ALISKE, M. A.; ZAGONEL, G.F.; COSTA, B.J.;; VEIGA, W.; SAUL, C.K.. Measurement of biodiesel concentration in a diesel oil mixture. Fuel, v. 86, p. 1461 - 1464, 2007.

BENTO, D. M.; BRAISCH, P.; MACHADO, M.I.; COSTA, J.A.; MARTINS, V. Biorremediação em ambiente impactado com óleo diesel. In: XVI Encontro de Química da 
Região Sul, Blumenau/SC. A Química como Ciência, Educação e Tecnologia. Blumenau, 2008.

CARDOSO, A.M. Sistema de informações para planejamento e resposta a incidentes de poluição marítima por derramamento de petróleo e derivados. 2007. Dissertação, COPPE - Universidade Federal do Rio de Janeiro, Rio de Janeiro, 2007.

DOMINGUEZ, A.; MENÉNDEZ, J.A.; PIS, P.P. Hydrogen rich fuel gas production from the pyrolysis of wet sewage sludge at high temperature. J. Anal. Appl. Pyrol., v.77, p.127132, 2006.

DUA, M.; SINGH, A.; SETHUNATHAN, N.; JOHRI, A.K. Biotechnology and bioremediation: successes and limitations. Appl. Microbiol. Biotech., volume 59, p. 143-152, 2002.

ERNESTRO, M. F. S. Poluição por Petróleo nos ambientes marinho e costeiro, Monografia, UNOPAR - Universidade Norte do Paraná, Itajubá, 2010.

FONTS, I.; AZUARA, M.; GEA, G.; MURILLO, M.B. Study of the pyrolysis liquids obtained from different sewage sludge. J. Anal. Appl. Pyrol., v. 85, p.184-191, 2009.

POKORNA, E.; POSTELMANS, N.; JENECEK, P.; SCHREURS, S.; CARLEER, R.; YPERMAN, J. Study of bio-oils and solids from flash pyrolysis of sewage sludges. Fuel, v. 88, p. 1344-1355, 2009.

RAHMAN, K.S.M.; BANAT, I.M.; THAHIRA, J. Bioremediation of gasoline contaminated soil by a bacterial consortium amended with poultry litter, coir pith and rhamnolipid biosurfactant. J. Bioresource Technol., v. 81, p. 25-32, 2002.

SOARES, I.P.; FONSECA, T.R.; PEREIRA, R.C.C.; FORTES, I.C.P. Determination of Biodiesel Adulteration with Raw Vegetable Oil from ATR-FTIR Data using Chemometric Tools. J. Braz. Chem. Soc. v.22, p.1229-1235,2011.

SOUZA, F.A.S.D; SALGUEIRO, A.A.; ALBUQUERQUE, C.D.C. Production of bioemulsifiers by Yarrowia lipolytica in sea water using diesel oil as carbon source. Braz. J. of Chem. Eng. v. 29, p. 61-67, 2011.

SILVA, E.; FILHO, A.M.; SA-CORREIA, I.; BURNS, R.G.; SHAW, L.J. Combined bioaugmentation and biostimulation to cleanup soil contaminated with high concentrations of atrazine. Environ. Sci. Technol., v. 38, p. 632-637, 2004. 